\title{
Analisis Tingkat Kapabilitas Layanan Perizinan Online Kabupaten Badung Menggunakan Framework COBIT 5
}

\author{
Ni Luh Made Uti Tiasmi ${ }^{1}$, I Made Candiasa ${ }^{2}$, Gede Indrawan ${ }^{3}$ \\ Program Pascasarjana \\ Universitas Pendidikan Ganesha \\ Singaraja, Indonesia \\ e-mail: ${ }^{1}$ utitiasmi22@gmail.com, ${ }^{2}$ candiasa@undiksha.ac.id, ${ }^{3}$ gindrawan@undiksha.ac.id \\ Diajukan: 5 Februari 2021; Direvisi: 29 Maret 2021; Diterima: 31 Maret 2021
}

\begin{abstract}
Abstrak
Analisis tingkat kapabilitas Layanan Perizinan Online (LAPERON) Badung dengan COBIT 5 bertujuan untuk mengetahui tingkat pencapaian dari sistem yang dibangun. COBIT 5 digunakan untuk mengukur kinerja sumber daya Teknologi Informasi (TI) dalammencapai visi dan misi organisasi. Analisis dimulai dengan melihat permasalahan yang adapada DPMPTSP Kabupaten Badung, kemudian dilakukan pemetaan terhadap strategi bisnis dengan enterprise goals dan IT related goals COBIT 5. Pengolahan data dan penilaian dilakukan dengan process assessment models dan analisis kesenjangan untuk menentukan tingkat kapabilitas LAPERON. Analisis menghasilkanfokus audit pada 7 domain proses COBIT 5 yaitu, Ensure Governance Framework Setting and Maintenance (EDM01), Manage the IT Management Framework (APO01), Manage Strategy (APO02), Manage Enterprise Architecture (APO03), Manage Human Resources (APO07), Manage Relationships (APO08), dan Manage Requirements Definition (BAI02). Teknik pengumpulan data yang digunakan adalah observasi, wawancara dan penyebaran kuesioner. Hasil analisis tingkat kapabilitas saat ini untuk domain EDMO1 dan APOO2 berada pada level 4 (predictable process). Sedangkan, untukdomain APO1, APO03, APO07, APO08, dan BAIO2 berada di level 3 (established process). Capabilitylevel tata kelola LAPERON yang diharapkan, yaitu pada level 5 (optimizing process). Sehing ga terdapat gap antara level kapabilitas saat ini denganyang diharapkan pada masing-masing domain EDM01 dan APO02 bernilai 1 gap, APO1, APO03, APO07, APO08, dan BAI02 bernilai 2 gap.
\end{abstract}

Kata kunci: Analisis, COBIT 5, Tingkat Kapabilitas.

Abstract

Analysis of the capability level of the Badung Online Licensing Service (LAPERON) with COBIT 5 aims to determine the noise level of the system being built. COBIT 5 is used to measure the performance of Information Technology (IT) resources in achieving the vision and mission of the organization. The analysis begins by looking at the problems that exist in the Badung Regency DPMPTSP, then mapping the business strategy with company goals and objectives related to IT COBIT 5. Data processing and inspection are carried out with a process assessment model and responsibility analysis to determine the level of LAPERON capability. The analysis resulted in an audit focus on the 7 domains of the COBIT 5 process, namely, Ensure Governance Framework Setting and Maintenance (EDM01), Manage IT Management Frameworks (APO01), Manage Strategies (APO02), Manage Company Architecture (APO03), Manage Human Resources (APO07), Manage Relationships (APO08), and Manage Requirements Definition (BAI02). The data techniques used were observation, interviews and questionnaires. The results of the current capabilitylevel analysis for the EDMO1 and APOO2 domains are at level 4 (predictable process). Meanwhile, the APO1, APO03, APO07, APOO8 and BAIO2 domains are at level 3 (a predetermined process). The expected level of LAPERON governance capabilities, namely at level 5 (optimization process). So that there is a gap between the current and expected capability levels in each of the EDMO1 and APOO2 domains worth 1 gap, APO1, APO03, APO07, APOO8, and BAIO2 are worth 2 gaps.

Keywords: Analysis, COBIT 5, Capability Level.

p-ISSN: 2089-1814; e-ISSN: 2460-3694; DOI: 10.30864/eksplora.v10i2.501 


\section{Pendahuluan}

Kabupaten Badung adalah salah satu kota di Provinsi Bali yang saat ini telah mengembangkan teknologi informasi sebagai salah satu faktor pendukung dalam pelaksanaan pelayanan publik untuk mewujudkan tata kelola pemerintahan yang baik (good Governance). Di mana, dalam organisasi pemerintahan telah diatur pada Peraturan Presiden Nomor 95 tahun 2018 tentang Sistem Pemerintahan Berbasis Elektronik (SPBE). Oleh karena itu penggunaan TI dan tata kelola TI sebagai tanggung ja wab eksekutif dan dewan direksi yang akan memastikan bahwa TI organisasi tersebut bisa mendukung dan menyampaikan tujuan strategis organisasi[1]. Melalui Dinas Penanaman Modal dan Pelayanan Terpadu Satu Pintu (DPMPTSP) Pemerintah Kabupaten (Pemkab) Badung mengesahkan layanan perizinan online (LAPERON) berbasis web dan Android pada tanggal28 Agustus 2019.

Penerapan LAPERON dalam mewujudkan target rencana pembangunan jangka menengah daerah dengan melihat misi kedua dan tujuan rencana strategis DPMPTSP Kabupaten Badung. Efektivitas dan efisiensi penerapan LAPERON diperoleh dengan melihat seberapa jauh tingkat kapabilitas tata kelola TI yang dilaksanakan. Tata kelola TI adalah suatu kerangka kerja yang digunakan untuk memastikan infrastruktur TI pada suatu organisasi bisa mendukung tercapainya strategi dan tujuan dari sebuah perusahaan. Evaluasi ta ta kelola perlu dilakukan agar keselarasan TI dengan tujuan suatu organisa si dapat dipastikan sebagai bentuk dukungan kepada organisasi dalam mencapai tujuannya [2]. Oleh karena itu, evaluasi dipandang perlu dilakukan untuk melihat tingkat tata kelola LAPERON.

Analisis data menggunakan process assessment models untuk memperoleh hasil penilaian dan analisis kesenjangan untuk menentukan tingkat kapabilitas LAPERON. Analisis juga dilakukan untuk mengetahui fokus domain proses COBIT 5 yang a kan digunakan sebagai acuan dala m evaluasi LAPERON. Evaluasi dilakukan dengan menggunakan framework Control Objectives for Information and Related Technologi (COBIT) versi 5. COBIT 5 merupakan genera si terbaru y ang digunakan untuk melakukan audit sistem mengenaitata kelola dan manajemen TI [3]. ISACA menerbitkan COBIT 5 pada bulan April 2012 sebagai "kerangka kerja untuk tata kelola dan pengelola an perusahaan TI". COBIT 5 mengkonsolidasikan COBIT4.1, Val IT dan Risk IT menjadi satu kerangka kerja yang bertindak sebagai kerangka kerja perusaha an yang selaras dan dapat diopera sikan dengan TOGAF dan ITIL [4]. Framework COBIT saat ini banyak dijadikan sebagai kerangka untuk menilaitata kelola TI. Hal ini ditandai dengan adanya pencapaian oleh COBIT dalam memperoleh penga kuan dari seluruh dunia sebagai framework terpercaya dalam bidang tata kelola TI [5].

Berdasarkan hal tersebut audit dilakukan dengan menggunakan domain IT Governance pada COBIT 5 yang berfokus pada ta ta kelola TI. Evalua si dilakukan berdasarkan kerangka kerja COBIT 5, yang dimodifikasi dan disesuaikan dengan kondisi yang terjadi pada tempat penelitian [6]. Hasil dari evaluasi tingkat kapabilitas pada domain proses yang terpilih nantinya dapat digunakan sebagai acuan dalam meningkatkan kualitas LAPERON bagi para pemangku kepentingan diDPMPTSP Kabupaten Badung.

\section{Metode Penelitian}

\subsection{COBIT 5}

COBIT atau Control Objectives for Information and Related Technology merupakan pedoman umum manajemen yang dikembangkan oleh IT Governance Institute (ITGI). COBIT yang dikembangkan secara berkelanjutan menjadi kerangka kerja yang dinilai paling lengkap dan menyeluruh [7]. COBIT 5 adalah generasi terbaru oleh panduan ISACA (Information Systems Audit and Control Association), di mana dalam penjelasannya COBIT 5 bukan lagi kerangkan kerja TI untuk diadopsi unit TI tapi sebagai kerangka kerja bisnis terhadap tata kelola manajemen TI. COBIT 5 memiliki 5 domain tata kelola yang dibagi ke dalam 2 fokus domain yaitu governance dan management. Pada domain governance dilakukan evaluasi (evaluating) pada kebutuhan yang digunakan untuk memastikan tujuan suatu organisasi dapat dicapai. Melihat kondisi dan apa yang dipilih oleh stakeholder, dengan melihat skala prioritas serta menga mbil keputusan sesuai arah yang ditetapkan (direction) dan melaksanakan dengan tetap melakukan pengawasan (monitoring). Sedangkan pada domain management terdiri dari Plans, Builds, Runs, and Monitors (PBMR), yang digunakan dalam mencapai tujuan suatu organisasi diperlukan penentuan keselarasan arah dan aktivitas organisasi [3]. Masing-masing domain tersebut menjelaskan cakupan rinci tentang pedoman audit ta ta kelola dan manajemen IT perusahaan secara luas. Ga mbaran tentang pembagian domain governance dengan management dapat dilihat pada Gambar 1 . 


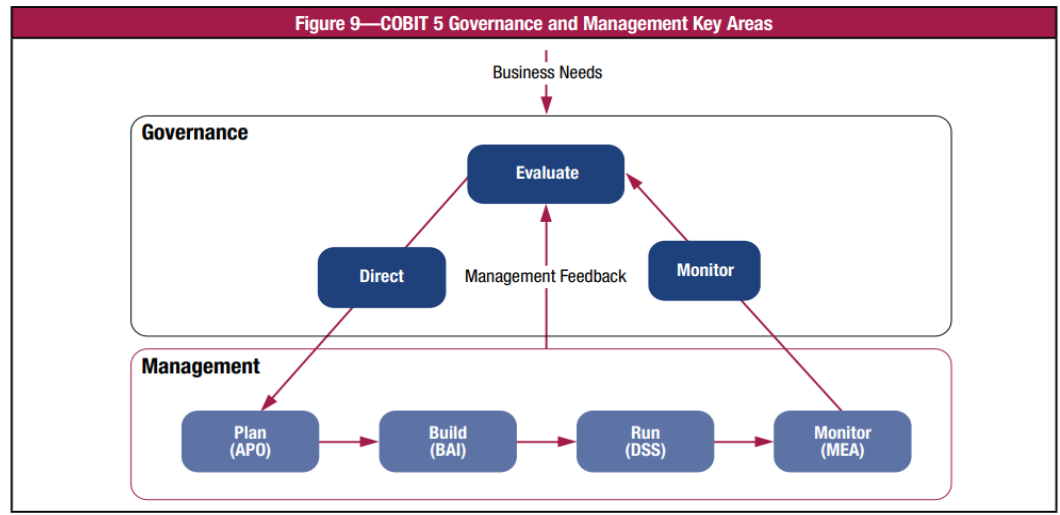

Gambar 1. Domain COBIT 5[8]

Model tata kelola dari framework COBIT 5 terdiri atas rangkaian terbaik proses TI untuk bermacam-macam kebutuhan manajemen, adanya kesenjangan pada risiko bisnis, dan ma salah teknis yang dapat dikelola. Pengaplikasian COBIT 5 pada perusahaan da pat membantu ta ta kelola dan manajemen TI menjadi lebih baik, penjelasan darikelima domain tersebut adalah sebagaiberikut [5]:

1. Evaluate, Direct and Monitor (EDM)

Domain ini adalah domain yang menangani tentang persetujuan dengan stakeholder, melakukan optimasi risiko dan optimalisasi sumber daya.

2. Align, Plan and Organise (APO)

Domain ini membuatkontribusi TI mencapaitujuan bisnis dengan mencakup strategidan taktik serta fokus pada tujuan sebuah organisasi.

3. Build, Acquire and Implement (BAI)

Domain BAI a dalah domain yang mencakup tentang solusi dan melakukan perubahan layanan untuk mencapai strategi dalam TI.

4. Deliver, Service and Support (DSS)

Domain yang berkaitan dengan dukungan layanan yang dibutuhkan oleh sistem, serta dukungan layanan bagi pengguna manajemen data dan fa silitas yang diperlukan dalam operasional.

5. Monitor, Evaluate and Assess (MEA)

Domain ini berkaitan dengan monitoring untuk memastikan semua proses dan arahan yang disediakan sudah diikuti

\subsection{Process Assesment Model}

Process Assesment Model (PAM) merupakan framework untuk pengukuran yang menyediakan dasar untuk menentukan tingkat kapabilitas suatu proses pada COBIT 5. Tujuan dari penilaian kapabilitas proses adalah untuk menginformasikan kepada manajemen leveleksekutif, jajaran direksi serta manajemen stakeholder mengenai kemampuan dari proses TI yang ada di dalam organisasi serta target perbaikan berdasarkan kebutuhan dari organisasi [5]. Penilaian COBIT 5 PAM didasarkan pada ISO/IEC 15504 atau dikenal sebagai Software Process Improvement and Capability Determination (SPICE) yang merupakan kerangka kerja atau standar untuk penilaian proses yang dikembangkan oleh ISO dan IEC [9]. Kapabilitas proses terdiri dari 6 tingkatan dari skala 0 sampai 5, seperti pada Gambar 2 . 


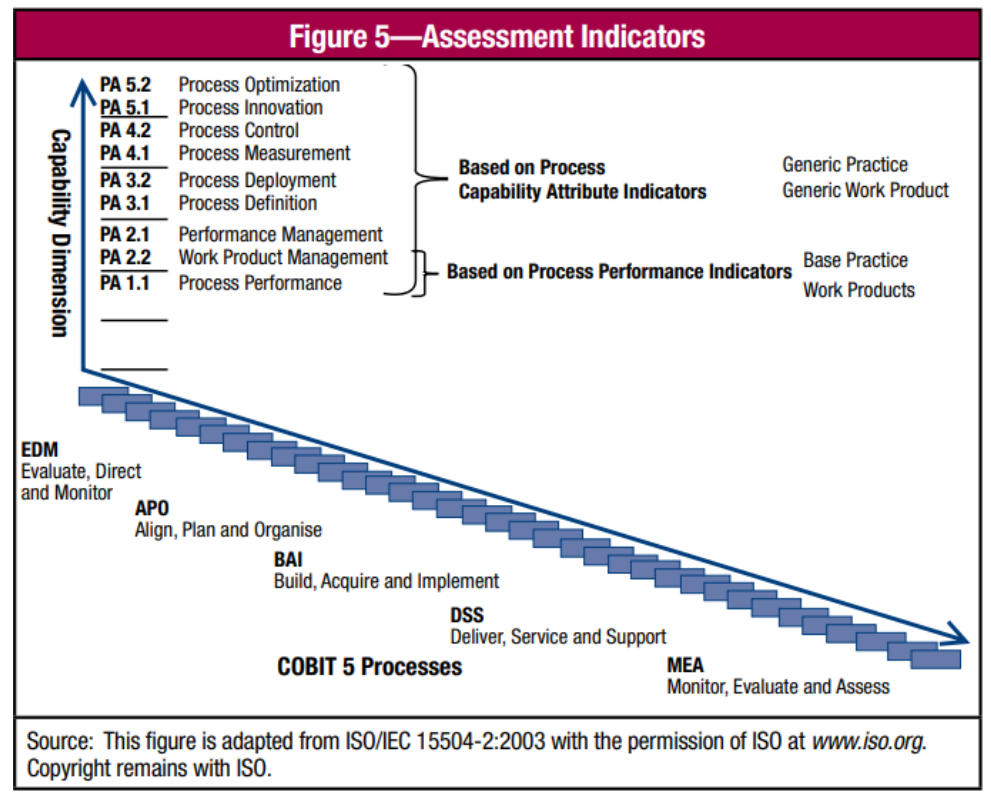

Gambar 2. Process Assesment Model [5].

Penilaian proses dilakukan berdasarkan model dua dimensi yang terdiri dari dimensi proses dan dimensi kapabilitas. Adapun tingkat skala yang dimaksud, yaitu:

1. Kapabilitas Level 0 (Incomplete process), di mana proses tidak diimplementasikan atau gagal mencapaitujuan dariproses itu sendiri.

2. Kapabilitas Level 1 (Performed process) di mana proses dikerjakan secara adhoc dan tidak terorganisasi oleh karenanya sangat tergantung pada kemampuan individual.

3. Kapabilitas Level 2 (Managed process) di mana proses yang dikerjakan telah direncanakan, dimonitor, didokumentasikan, dan disesuaikan agar dapat memenuhi objektivitas yang telah diidentifikasi sebelumnya.

4. Kapabilitas Level 3 (Established process) di mana proses yang diimplementasikan sebelumnya dilaksanakan berdasarkan standar dari suatu proses, diimplementasikan sebagai proses yang terdefinisi yang mampu mencapai outcome dari proses tersebut.

5. Kapabilitas Level 4 (Predictable process) di mana proses yang di implementasikan sebelumnya, sekarang diimplementasikan dengan menggunakan batasan yang terdefinisi untuk mencapai output dari proses tersebut.

6. Kapabilitas Level 5 (Optimizing process), proses sudah dikembangkan secara berkelanjutan untuk mencapaitujuan organisasi.

\subsection{Alur Penelitian}

Alur penelitian ini dimulai dengan tahap 1 initiate programme untuk mengidentifikasi penggerak perubahan saat ini dan diciptakan suatu keinginan untuk melakukan perubahan di level manajemen eksekutif. Tahap 2 define problems and opportunities untuk melakukan identifika si tentang hasil tahap 1 yaitu berupa tujuan yang yang memiliki hubungan antara TI dengan strategi dan risiko dan tujuan perusahaan atau organisasi diprioritaskan. Tahap 3 define road map yang merupakan tahapan untuk mengumpulkan data dan mela kukan perhitungan terhadap data yang diperoleh. Tahap 4 plan programme untuk melakukan analisis dan perencanaan solusi praktis yang layak dilaksanakan dengan cara mendefinisikan hasil dari tahap 3. Dan terakhir tahap 5 execute plan dilakukan menyediakan pelaksanaan solusi yang disusulkan dan memberikan pemaparan mengenai hasil rekomendasiperbaikan. Tahapan yang dilakukan pada penelitian ini dilakukan tahapan seperti yang tergambar yang terdapat pada Gambar 3 . 


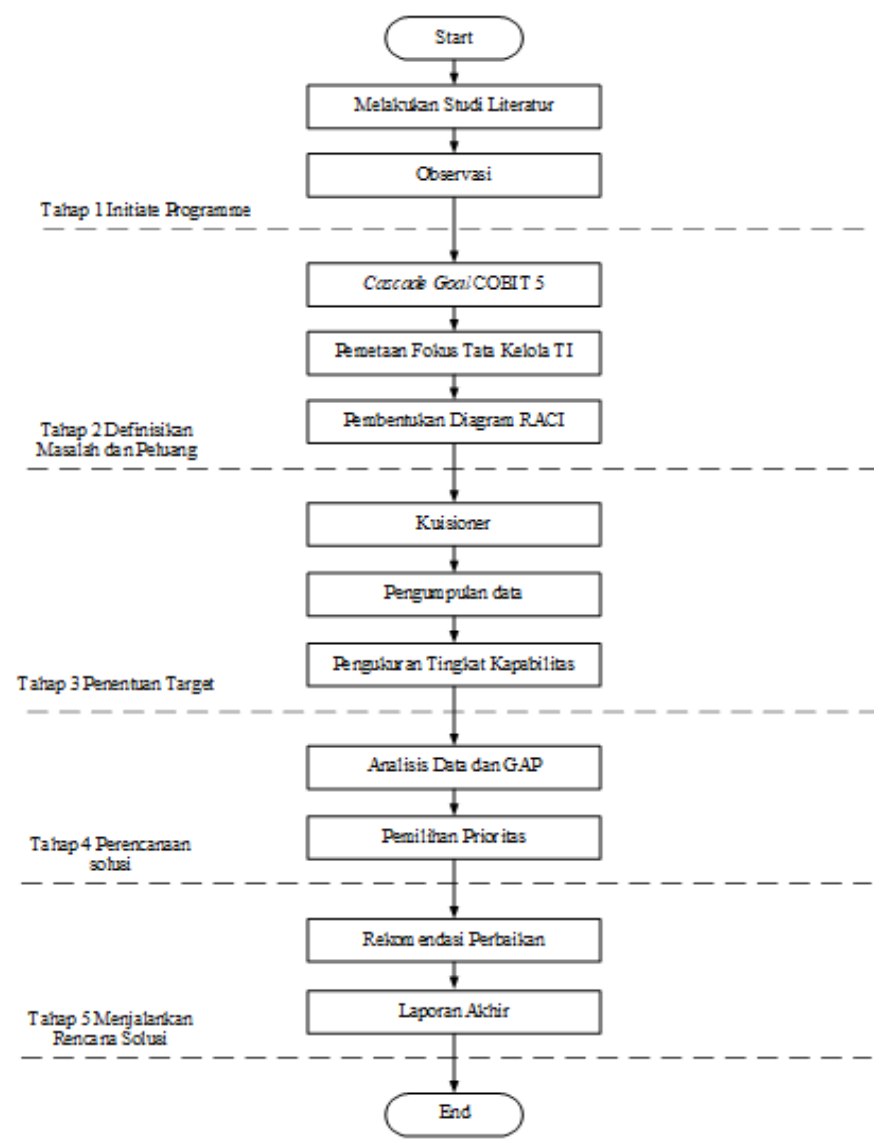

Gambar 3. Alur penelitian.

\section{Hasil dan Pembahasan}

\subsection{Pemetaan Enterprise Goal dengan Rencana Strategis dan Tujuan LAPERON.}

Pemetaan terhadap 17 Enterprise Goal (EG) COBIT 5 dengan 3 rencana strategis organisasi dan 4 tujuan LAPERON terletak pada 2 BSC dimension yang berkaitan yaitu financial dan customer. Ha sil dari pemetaan, menunjukkan keterkaitan rencana strategis DPMPTSP Kabupaten Badung dengan EG COBIT 5. Di mana dari hasil pemetaan tersebut diperoleh sebanyak $2 E G$ yang terletak pada EG1 yaitu nilai pemangku kepentingan dari investasi bisnis dan EG6 buda ya layanan berorientasi pelanggan. Hasil pemetaan lebih jelas dapat dilihat pada Tabel1.

Tabel 1. Pemetaan enterprise goals dengan rencana strategis perusahaan.

\begin{tabular}{|c|c|c|c|c|}
\hline $\begin{array}{c}\text { BSC } \\
\text { Dimension }\end{array}$ & Kode & Enterprise Goals & Rencana Strategis & Tujuan LAPERON \\
\hline Financial & EG1 & $\begin{array}{l}\text { Nilai pemangku kepentingan } \\
\text { dari investasi bisnis. }\end{array}$ & $\begin{array}{l}\text { Meningkatkan kebutuhan } \\
\text { investasi. }\end{array}$ & $\begin{array}{l}\text { Meningkatkan kecepatan, } \\
\text { ketepatan dan transparansi dalam } \\
\text { pelayanan perizinan }\end{array}$ \\
\hline \multirow{3}{*}{ Customer } & \multirow{3}{*}{ EG6 } & \multirow{3}{*}{$\begin{array}{l}\text { Budaya layanan berorientasi } \\
\text { pelanggan }\end{array}$} & \multirow{2}{*}{$\begin{array}{l}\text { Meningkatkan kepuasan } \\
\text { masyarakat terhadap } \\
\text { pelayanan publik di } \\
\text { bidang perizinan dan non } \\
\text { perizinan }\end{array}$} & $\begin{array}{l}\text { Memberikan pelayanan perizinan } \\
\text { dan non perizinan yang adadi } \\
\text { kabupaten badung dengan } \\
\text { kemudahan akses. }\end{array}$ \\
\hline & & & & $\begin{array}{l}\text { Untuk menyelenggarakan } \\
\text { pelayanan perizinan online di } \\
\text { Kabupaten Badung demi } \\
\text { meningkatkan kepuasan } \\
\text { masyarakat. }\end{array}$ \\
\hline & & & $\begin{array}{l}\text { Meningkatkan kapasitas } \\
\text { dan integritas aparatur } \\
\text { dalam penyelenggaraan } \\
\text { pelayanan prima. }\end{array}$ & $\begin{array}{l}\text { Memberi perubahan dan } \\
\text { transformasi terhadap pola } \\
\text { pelayanan yang semula bersifat } \\
\text { konvensional berubah perlahan } \\
\text { menjadi bersifat online. }\end{array}$ \\
\hline
\end{tabular}

Analisis Tingkat Kapabilitas Layanan Perizinan Online Kabupaten Badung Menggunakan Framework COBIT 5 (Ni Luh Made Uti Tiasmi) 


\subsection{Pemetaan Enterprise Goal dengan IT-Related Goal}

Fokus pemetaan EG yang digunakan adalah bersifat primer $(\mathrm{P})$ terhadap tujuan organisasi. Terdapat 2 tujuan perusahaan yang telah diidentifika si pada Tabel 1 yang selanjutnya dipetakan dengan ITRelated Goal (IT-RG) dalam COBIT 5 seperti pada Tabel2. Dari hasil pemetaan pada Tabel 2 diperoleh 6 (enam) dimensi IT-Related Goals yang bersifat primer. Berda sarkan misikedua yang menjadida sar sa saran strategis DPMPTSP Kabupaten Badung yaitu memantapkan kualitas pelayanan publik melalui penerapan teknologi informasi dan komunikasi. Serta tujuan dan sasaran strategis jangka menengah DPMPTSP Kabupaten Badung yaitu terwujudnya pelayanan prima sesuai kebutuhan dan harapan masyarakat dalam bidang penanaman modal, perizinan dan non perizinan.

Tabel 2. Pemetaan IT-Related Goals dengan Enterprise Goals.

\begin{tabular}{|c|c|c|c|c|}
\hline & \multicolumn{2}{|r|}{ Tujuan terkait TI } & \multirow{2}{*}{$\begin{array}{c}\begin{array}{c}\text { Nilai Pemangku Kepentingan } \\
\text { dari Investasi Bisnis }\end{array} \\
\text { EG-1 } \\
\text { Financial } \\
\end{array}$} & \multirow{2}{*}{$\begin{array}{c}\text { Budaya Layanan } \\
\text { Berorientasi Pelanggan } \\
\boldsymbol{E G - 2} \\
\text { Costumer } \\
\end{array}$} \\
\hline & & & & \\
\hline \multirow{3}{*}{ 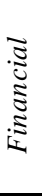 } & $\begin{array}{l}I T-R G \\
\quad 1\end{array}$ & Penyelarasan TI dengan strategi bis nis & $\mathrm{P}$ & $\mathrm{P}$ \\
\hline & $\begin{array}{c}I T-R G \\
3 \\
\end{array}$ & $\begin{array}{l}\text { Komitmen manajemen eksekutif untuk membuat } \\
\text { keputusan terkait IT }\end{array}$ & $\mathrm{P}$ & \\
\hline & $\begin{array}{l}I T-R G \\
5\end{array}$ & $\begin{array}{l}\text { Realisasi manfaat dari in vestasi yang } \\
\text { memungkinkan IT dan portofolio layanan }\end{array}$ & $\mathrm{P}$ & \\
\hline 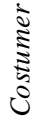 & $\begin{array}{l}I T-R G \\
7\end{array}$ & $\begin{array}{l}\text { Pengiriman layanan TI sesuai dengan persyaratan } \\
\text { bisnis }\end{array}$ & $\mathrm{P}$ & $\mathrm{P}$ \\
\hline \multirow{2}{*}{ 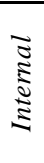 } & $\begin{array}{c}I T-R G \\
11 \\
\end{array}$ & $\begin{array}{l}\text { Optimalisasi aset, sumber daya, dan kemampuan } \\
\text { TI }\end{array}$ & $\mathrm{P}$ & \\
\hline & $\begin{array}{c}I T-R G \\
13\end{array}$ & $\begin{array}{l}\text { Pengiriman program memberikan manfaat, tepat } \\
\text { waktu, sesuai anggaran dan memenuhi pers yaratan } \\
\text { serta standar kualitas }\end{array}$ & $\mathrm{P}$ & \\
\hline
\end{tabular}

\subsection{Pemetaan IT-Related Goal dengan Proses COBIT 5}

Pemetaan dilakukan terhadap 37 domain proses COBIT 5 dengan dimensi IT-RG 1 yaitu penyela ra san teknologi informasi dengan strategi bisnis. Proses pemeta an tersebut menghasilkan 10 domain proses COBIT 5 yang bersifat primer (P). Hasil pemeta an IT-Related Goals dengan domain proses COBIT 5 selanjutnya dianalisis kembali. Analisis tersebut menghasilkan 7 domain proses yang relevan terhadap perma sa lahan yang a kan audit. Proses ini digunakan sebagai acuan dalam audit LAPERON. Domain proses COBIT 5 yang relevan da pat dilihat pada Tabel3.

Tabel 3. Proses COBIT 5 Relevan

\begin{tabular}{ccc}
\hline No. & Proses COBIT 5 & Relevan \\
\hline 1 & EDM01 & Ya \\
\hline 2 & APO01 & Ya \\
\hline 3 & APO02 & Ya \\
\hline 4 & APO03 & Ya \\
\hline 5 & APO07 & Ya \\
\hline 6 & APO08 & Ya \\
\hline 7 & BAI02 & Ya \\
\hline
\end{tabular}

\subsection{Responden}

Identifikasi responden dilakukan dengan pemetaan diagram RACI. Pada diagram RACI digambarkan tentang pihak-pihak yang terlibat pada setiap langkah praktiknya yaitu Responsible (R), Accountable (A), Consulted (C), dan Informed (I). Penentuan dia gram RACI dilakukan untuk menunjukkan peran-peran (roles) dari para pemangku kepentingan LAPERON. Pemeta an responden dilakukan pada 26 role COBIT 5 dengan enablers process LAPERON. Di mana dari 26 roles COBIT 5 diperoleh 12 roles pada yang dipetakandengan 14 roles pada DPMPTSP Kabupaten Badung yang pembagiannya dapat dilihat pada Tabel4. 
Tabel 4. Role Responden

\begin{tabular}{cl}
\hline Role pada COBIT 5 & \multicolumn{1}{c}{ Role pada DPMPTSP Kabupaten Badung } \\
\hline Chief Executive Officer & Kepala Dinas PMPTSP Kabupaten Badung \\
\hline Chief Financial Officer & Kepala Subbagian Keuangan \\
\hline Chief Operating Officer & Sekretaris DPMPTSP Kabupaten Badung \\
\hline \multirow{3}{*}{ Business Process Owners } & Kepala Bidang Pelayanan Perizinan Pemerintahan dan Pembangunan \\
\cline { 2 - 2 } & Kepala Bidang Pelayanan Perizinan Ekonomi \\
\cline { 2 - 2 } & Kepala Bidang Pelayanan Perizinan Kesejahteraan Rakyat dan Non Perizinan \\
\hline Project Management Office & Kepala Bidang Program dan Informasi \\
\hline Head Human Resources & Kepala Subbagian UMUMDPMPTSP \\
\hline Chief Information Officer & Kepala Staf Sistem Informasi Bidang Program \\
\hline Head Development & Ketua tim pengembang LAPERON \\
\hline Head IT Operations & Administrator Operasi TILAPERON \\
\hline Head IT Administration & Adminis trator TI LAPERON \\
\hline Information Security Manager & Administrator Keamanan Informasi LAPERON \\
\hline Business Continuity Manager & Administrator Kesinambungan TI LAPERON \\
\hline
\end{tabular}

\subsection{Penilaian}

Penilaian dengan menggunakan metode COBIT 5 pada penelitian ini dilakukan untuk membuat usulan kebijakan. Usulan Kebijakan atau rekomendasi perbaikan diperoleh dengan melihat tingkat kapabilitas LAPERON pada DPMPTSP Kabupaten Badung. Penilaian tingkat kapabilitas menggunakan perhitungan dalam bentuk indeks dengan rumus yang dirujuk dari penelitian Agoan, 2017 [10] tentang analisis tingkat kapabilitas TI dengan framework COBIT 5, seperti pada Persama an (1).

Pada Persamaan (1) nilai indeks merupakan nilai tingkat kapabilitas TI, jumlah ja waban adalah total nilai yang diberikan oleh responden, sedangkan penyataan kuesioner adalah banyaknya jumlah pernyataan yang terdapat da lam kuesioner.

$$
\text { Nilai Indeks }=\frac{\sum \text { Jawaban }}{\sum \text { Pernyataan Kuesioner }}
$$

Contoh perhitungan dari persamaan (1):

Tabel 5. Data Contoh Perhitungan.

\begin{tabular}{ccc}
\hline Level Sub Domain & No. Pernyataan & Nilai $(\boldsymbol{\%})$ \\
\hline \multirow{3}{*}{ Level 0 } & 1 & 90 \\
\cline { 2 - 3 } & 2 & 80 \\
\cline { 2 - 3 } & 3 & 80 \\
\cline { 2 - 3 } & 4 & 90 \\
\cline { 2 - 3 } Level 1 & 5 & 80 \\
\cline { 2 - 3 } & 1 & 80 \\
\cline { 2 - 3 } & 2 & 80 \\
\cline { 2 - 3 } & 3 & 80 \\
\hline
\end{tabular}

Berdasarkan data pada Tabel 5 di mana, satu sub domain memiliki 2 level dengan pernyataan masing-masing pada level 0 berjumlah 5 dan pada level 1 berjumlah 4 dengan perolehan nilai seperti yang tertera dalam tabel. Selanjutnya untuk memperoleh nilai indeks pada masing-masing level maka, angka yang a da pada kolom nilai akan ditambahkan dan dibagi sesuai dengan jumlah pernyataan kuesioner di setiap levelnya. Sehingga, akan diperoleh hasil indeks persenta se pada masing-masing level sub domain.

Nilai Indeks level $0=\frac{90 \%+80 \%+80 \%+90 \%+80 \%}{5}=\frac{420 \%}{5}=84 \%$

Nilai Indeks level $1=\frac{80 \%+80 \%+80 \%+90 \%}{4}=\frac{330 \%}{4}=82,5 \%$

Maka, setelah dilakukan perhitungan diperoleh hasil nilai indeks sebesar $84 \%$ untuk level 0 dan $82,5 \%$ untuk level 1 yang nantinya akan digunakan untuk menentukan level kapabilitas pada sub domain COBIT 5. 


\subsection{Hasil Analisis Tingkat Kapabilitas Saat Ini}

Perhitungan hasil analisis tingkat kapabilitas adalah proses yang dilakukan agar kondisi tingkat kapabilitas TI pada aplikasi LAPERON Badung saat ini (as is) dan yang diharapkan (to be) dapat diketahui. Analisis dilaksanakan berdasarkan perolehan nilai indeks sesuai Persamaan (1) dari hasil kuesioner yang diberikan kepada 14 responden dengan 7 proses domain COBIT 5 sesuai pada Tabel3. Hasil analisis dan perolehan nilai as is pada LAPERON Badung dijelaskan pada Tabel 6 dengan menampilkan domain proses sebagai acuan evaluasi, level dan nilai yang diperoleh, level kapabilitas saat ini, dan indikator perolehan nilai dari setiap domain proses COBIT 5.

Tabel 6. Analisis tingkat kapabilitas LAPERON saat ini.

\begin{tabular}{|c|c|c|c|c|}
\hline Proses & Level & Nilai (\%) & Level Kapabilitas saat ini & Indikator \\
\hline \multirow{6}{*}{ EDM01 } & 0 & 95 & \multirow[t]{6}{*}{4 (predictable process) } & \multirow{6}{*}{$\begin{array}{l}\text { Telah memilikiproses yang mengatur } \\
\text { tentang pengelolaan tata kelola TI pada } \\
\text { aplikasi LAPERON. }\end{array}$} \\
\hline & 1 & 88 & & \\
\hline & 2 & 86 & & \\
\hline & 3 & 86 & & \\
\hline & 4 & 69 & & \\
\hline & 5 & - & & \\
\hline \multirow[t]{6}{*}{ APO01 } & 0 & 97 & \multirow[t]{6}{*}{3 (established process) } & \multirow{6}{*}{$\begin{array}{l}\text { Telah memilikiframework manajemen } \\
\text { untuk LAPERON dalam usaha memenuhi } \\
\text { persyaratan tata kelola. }\end{array}$} \\
\hline & 1 & 86 & & \\
\hline & 2 & 86 & & \\
\hline & 3 & 83 & & \\
\hline & 4 & - & & \\
\hline & 5 & - & & \\
\hline \multirow[t]{6}{*}{$\mathrm{APO} 02$} & 0 & 95 & \multirow[t]{6}{*}{4 (predictable process) } & \multirow{6}{*}{$\begin{array}{l}\text { Telah mengelola s trategi TI pada aplikasi } \\
\text { LAPERON untuk mengatasi permas alahan } \\
\text { yang terjadi dan sebisa mungkin melakukan } \\
\text { pembaharuan. }\end{array}$} \\
\hline & 1 & 89 & & \\
\hline & 2 & 86 & & \\
\hline & 3 & 79 & & \\
\hline & 4 & 67 & & \\
\hline & 5 & - & & \\
\hline \multirow{6}{*}{ APO03 } & 0 & 98 & \multirow{6}{*}{3 (established process) } & \multirow{6}{*}{$\begin{array}{l}\text { Telah mampu mengelola arsitektur layanan } \\
\text { TI pada LAPERON. }\end{array}$} \\
\hline & 1 & 86 & & \\
\hline & 2 & 79 & & \\
\hline & 3 & 71 & & \\
\hline & 4 & - & & \\
\hline & 5 & - & & \\
\hline \multirow[t]{6}{*}{ APO07 } & 0 & 98 & \multirow[t]{6}{*}{3 (established process) } & \multirow{6}{*}{$\begin{array}{l}\text { Telah cukup mampu mengelola sumber } \\
\text { daya manusiapada perusahaan dengan } \\
\text { memenuhi persyaratan bisnis untuk } \\
\text { penyelaras an aplikasi yang tersedia saat ini. }\end{array}$} \\
\hline & 1 & 88 & & \\
\hline & 2 & 85 & & \\
\hline & 3 & 73 & & \\
\hline & 4 & - & & \\
\hline & 5 & - & & \\
\hline \multirow[t]{6}{*}{ APO08 } & 0 & 98 & \multirow[t]{6}{*}{3 (established process) } & \multirow{6}{*}{$\begin{array}{l}\text { Telah cukup mampu mengelola sumber } \\
\text { daya manusiapada perusahaan dengan } \\
\text { memenuhi persyaratan bisnis untuk } \\
\text { penyelarasan aplikasi yang tersedia saat ini. }\end{array}$} \\
\hline & 1 & 90 & & \\
\hline & 2 & 87 & & \\
\hline & 3 & 77 & & \\
\hline & 4 & - & & \\
\hline & 5 & - & & \\
\hline \multirow[t]{6}{*}{ BAI02 } & 0 & 98 & \multirow[t]{6}{*}{3 (established process) } & \multirow{6}{*}{$\begin{array}{l}\text { Telah mampu menentukan persyaratan } \\
\text { bisnis untuk pengoptimalan kinerja } \\
\text { program LAPERON. }\end{array}$} \\
\hline & 1 & 88 & & \\
\hline & 2 & 86 & & \\
\hline & 3 & 76 & & \\
\hline & 4 & - & & \\
\hline & 5 & - & & \\
\hline
\end{tabular}

\subsection{Hasil Analisis Kesenjangan}

Ana lisis kesenjangan memiliki tujuan agarkesenjangan yang terjadi pada tata kelola LAPERON saat ini dengan yang diharapkan (expected capability level) dapat diketahui. Current capability level merupakan nilai rata-rata tingkat kapabilitas hasil evaluasi pada domain proses COBIT 5. Expected capability level ada la nilai target kapabilitas ta ta kelola TI yang diharapkan. Berdasarkan hasil kuesioner dan wawancara target tingkat kapabilitas TI pada LAPERON Badung yang diharapkan adalah pada level 5. Untuk mengetahuikesenjangan (gap) antara kondisi to be dengan hasil pengukuran capability level as is dapat dilihat pada Tabel7. Di mana, pada Tabel 6 menampilkan nilai as is, to be, dan gap dari domain proses COBIT 5 yang diperoleh dari hasil ana lisis pada Tabel6. 
Tabel 7. Analisis Kesenjangan.

\begin{tabular}{|c|c|c|c|}
\hline \multirow{2}{*}{ Proses COBIT 5} & \multicolumn{2}{|c|}{ Tingkat Kapabilitas } & \multirow{2}{*}{$\begin{array}{c}\text { Kesenjangan } \\
(\text { Gap }=\text { To be }- \text { As is })\end{array}$} \\
\hline & As is & Tobe & \\
\hline EDM01 & 4 & 5 & 1 \\
\hline APO01 & 3 & 5 & 2 \\
\hline $\mathrm{APO} 02$ & 4 & 5 & 1 \\
\hline APO03 & 3 & 5 & 2 \\
\hline APO07 & 3 & 5 & 2 \\
\hline APO08 & 3 & 5 & 2 \\
\hline BAI02 & 3 & 5 & 2 \\
\hline
\end{tabular}

\section{Kesimpulan}

Analisis tingkat kapabilitas tata kelola LAPERON pada DPMPTSP Kabupaten Badung, berfokus pada IT-Related Goals COBIT 5 yaitu Alignment of IT and business strategy. Pengumpulan data dilakukan dengan cara observasi, wawancara dan penyebaran kuesioner kepada responden yang berhubungan langsung dengan enabler proses. Evaluasi tingkat kapabilitas dilakukan pada 7 domain proses COBIT 5 yaitu,EDM01, APO01, APO02, APO03, APO07, APO08, dan BAI02. Hasil analisis capabilitylevel saat ini untuk domain proses EDM01 dan APO02 adalah berada pada level4 (predictable process), ang artinya instansi telah melakukan monitoring, pengukuran, dan prediksi terhadap strategi bisnis LAPERON. Sedangkan pada proses APO01, APO03, APO07, APO08, dan BAI01 berada di level 3 (established process), yang artinya instansi telah mengembangkan strategi yang ada secara efektif bersama dengan kebutuhan infrastruktur LAPERON. Capability level yang diharapkan berdasarkan hasil wa wanca ra adalah berada pada level 5 (optimizing process). Hasil analisis gap antara nilai capability level saat ini dan yang diharapkan memperoleh nilai gap pada domain proses EDM01 dan APO02 adalah 1. Sedangkan pada domain proses APO01, APO03, APO07, APO08, dan BAI02 nilai gap adalah 2. Berdasarkan haltersebut hasil analisis COBIT 5 pada LAPERON dapat dijadikan acuan dalam perbaikan sistem tata kelola LAPERON agar capability level yang diharapkan dapat tercapai.

\section{Daftar Pustaka}

[1] R. R. Suryono, D. Darwis, and S. I. Gunawan, "Audit Tata Kelola Teknologi Informasi Menggunakan Framework Cobit 5 (Studi Kasus: Balai Besar Perikanan Budidaya Laut Lampung)," J. Teknoinfo, vol. 12, no. 1, pp. 16-12,2018, doi: 10.33365/jti.v12i1.38.

[2] S. Fajarwati, S. Sarmini, and Y. Septiana, "Evaluasi Tata Kelola Teknologi Informasi Menggunakan Kerangka Kerja COBIT 5," JUITA J. Inform., vol. 6, no. 2, pp. 73-80, 2018, doi: 10.30595/juita.v6i2.2019.

[3] ISACA, COBIT 5: A business framework for Governance and Management of Enterprise IT. 2012.

[4] W. Riyadi, "Analisis Sistem Informasi Akademik dengan Cobit framework," J. Ilm. Media Sisfo, vol. 12, no. 1, pp. 954-965, 2018.

[5] ISACA, COBIT 5: Process Assessment Model(PAM). ISA, 2013.

[6] I. G. L. A. R. Putra, B. L. Sinaga, and I. Wisnubhadra, "Evaluasi Tata Kelola Sistem Informasi Akademik Berbasis COBIT 5 di Universitas Pendidikan Ganesha,” J. Buana Inform., 2015, doi: 10.24002/jbi.v6i4.460.

[7] O. Liandiand F. Fitria, "Evaluasi Tata Kelola Framework COBIT 5 pada Dina sependudukan dan Pencatatan Sipil," POSITIF J. Sist. dan Teknol. Inf., vol. 5, no. 2, pp. 111-116, 2019, doi: 10.31961/positif.v5i2.828.

[8] ISACA, COBIT 5 : Enabling Processes. 2012.

[9] T. Kristanto, L. Andri Lestari, J. Teknik Informatika, I. Teknologi Adhi Tama Surabaya, and J. Arief Rachman Hakim, "ANALISIS TINGKAT KEMATANGAN E-GOVERNMENT MENGGUNAKAN FRAMEWORK COBIT 5 (STUDI KASUS: DINAS PERDAGANGAN DAN PERINDUSTRIAN KOTA SURABAYA)," Semin. Nas. Sist. Inf. Indones., vol. 5, 2016.

[10] T. S. Agoan, H. F. Wowor, and S. Karouw, "Analisa Tingkat Kematangan Teknologi Informasi Pada Dinas Komunikasi Dan Informatika Kota Manado Menggunakan Framework COBIT 5 Domain Evaluate, Deirect, Monitor (EDM) dan Deliver, Service, and Support (DSS)," J. Tek. Inform., 2017, doi: 10.35793/jti.10.1.2017.15627. 